\title{
Impacto da Covid-19 no funcionamento das clínicas de radiologia odontológicas no Nordeste do Brasil
}

\author{
Impact of Covid-19 on the operation of dental radiology clinics in Northeastern Brazil
}
Impacto de Covid-19 en el funcionamiento de clínicas de radiologia dental en el noreste de Brasil

Mathias Antonio Costa de Sousa ${ }^{1 *}$, Vanessa Beatriz Jales Rego ${ }^{1}$, Nathan Felipe de Brito Lima ${ }^{1}$, Lara Danúbia Galvão de Souza1, Lorena Layanne Pereira Custódio ${ }^{1}$, Ana Tatiana Gonzalez de Melo $^{2}$, Abrahão Alves de Oliveira Filho ${ }^{1}$, Camila Helena Machado da Costa Figueiredo ${ }^{1}$, Joab Cabral Ramos $^{3}$, Manuella Santos Carneiro Almeida ${ }^{1}$.

\section{RESUMO}

Objetivo: Avaliar o funcionamento e as medidas de segurança das clínicas de radiologia odontológica na região nordeste do Brasil, durante a pandemia da COVID-19. Métodos: Trata-se de uma abordagem indutiva, com procedimento estatístico-descritivo e técnica de observação indireta. Os dados foram coletados no período de março a julho de 2020, através de sítios eletrônicos (homepages) e perfis de redes sociais das clínicas de radiologia odontológica dos estados do nordeste do Brasil, sendo selecionadas 162 clínicas. Resultados: As clínicas de radiologia odontológica apresentam um alto risco para disseminação da COVID19. Para isso, foram necessárias atualizações nos protocolos de biossegurança destes âmbitos. A amostra apresentou que $48,14 \%$ das clínicas fecharam no mês de março e que $31,48 \%$ realizaram atendimento emergencial. Medidas como evitar radiografias intrabucais e dar preferência às extrabucais foram adotadas e, com o intuito de minimizar o contágio, a Teleodontologia foi utilizada por $58,64 \%$ dessas, disponibilizando os resultados dos exames por meio de ferramentas digitais. Conclusão: Os resultados do presente estudo revelaram a importância da implementação das normas de segurança, adotadas pelos órgãos de saúde, e a necessidade da evolução da biossegurança na rotina clínica da radiologia odontológica.

Palavras-chave: Clínicas de radiologia odontológica, COVID-19, Nordeste.

\begin{abstract}
Objective: To evaluate the functioning and safety measures of dental radiology clinics in the northeast of Brazil, during a COVID-19 pandemic. Methods: This is an inductive approach, with a statistical-descriptive procedure and indirect observation technique. Data were collected from March to July 2020, through electronic sites (homepages) and profiles of social networks of dental radiology clinics in the northeastern states of Brazil, with 162 clinics selected. Results: Dental radiology clinics present a high risk for the spread of COVID-19. To this end, they have been updated in the biosafety protocols in these areas. The sample presented that $48.14 \%$ of clinics closed in March and that $31.48 \%$ performed emergency care. Measures such as avoiding oral x-rays and giving preference to oral ones were adopted and, in order to minimize contagion, a teleodontology was used by $58.64 \%$ of these, making the results of the exams available through digital tools. Conclusion: The results of the present study revealed the importance of implementing safety standards, adopted by health agencies, and the need for the evolution of biosafety in the clinical routine of dental radiology.
\end{abstract}

Keywords: Dental radiology clinics, COVID-19, Northeast.

1 Universidade Federal de Campina Grande (UFCG), Patos - PB. *E-mail: mathias_sousa@hotmail.com

${ }^{2}$ Associação Brasileira de Odontologia (ABO), João Pessoa - PB.

3 Universidade Estadual de Campinas (UNICAMP), Campinas - SP. 


\section{RESUMEN}

Objetivo: Evaluar el funcionamiento y las medidas de seguridad de las clínicas de radiología dental en el noreste de Brasil, durante la pandemia de COVID-19. Métodos: Se trata de un abordaje inductivo, con procedimiento estadístico-descriptivo y técnica de observación indirecta. Los datos fueron recolectados de marzo a julio de 2020, a través de sitios electrónicos (homepages) y perfiles de redes sociales de clínicas de radiología dental en los estados del noreste de Brasil, con 162 clínicas seleccionadas. Resultados: Las clínicas de radiología dental presentan un alto riesgo de propagación de COVID-19. Para eso, se requirieron actualizaciones en los protocolos de bioseguridad en estas áreas. La muestra arrojó que el $48,14 \%$ de las clínicas cerraron en marzo y que el 31,48\% brindó atención de emergencia. Se adoptaron medidas como evitar las radiografías intraorales y dar preferencia a las orales y, para minimizar el contagio, el $58,64 \%$ de ellas utilizó la Teleodontología, poniendo a disposición los resultados de los exámenes a través de herramientas digitales. Conclusión: Los resultados del presente estudio revelaron la importancia de implementar estándares de seguridad, adoptados por las agencias de salud, y la necesidad de la evolución de la bioseguridad en la rutina clínica de la radiología dental.

Palabras clave: Clínicas de radiología dental, COVID-19, Noreste.

\section{INTRODUÇÃO}

A doença COVID-19, causada pelo vírus denominado SARS-CoV-2, é o sétimo coronavírus conhecido por infectar seres humanos, que pode causar uma doença grave (ANDERSEN KG, et al., 2020). Essa afecção viral tem uma alta velocidade de propagação, com números básicos de reprodução $\left(R_{0}\right)$, variando de 1.6 a 4.1, revelando-se superior ao $R_{0}$ da $\mathrm{H} 1 \mathrm{~N} 1 \mathrm{em}$ 2009, que foi entre 1.3 e 1.8 (LANA RM, et al., 2020). É um dos principais patógenos que afeta fundamentalmente o sistema respiratório humano na atualidade, o qual já acarretou impactos inestimáveis, afetando direta e (ou) indiretamente a saúde e a economia da população mundial (ROTHAN HA e BYRAREDDY SN, 2020; BRITO SBP, et al., 2020).

A COVID-19 foi detectada no Brasil durante a 9a semana epidemiológica de 2020 e, desde então, houve um aumento exponencial de casos devido à alta capacidade de transmissão do SARS-COV-2, sendo declarado pela Organização Mundial de Saúde (OMS), em janeiro de 2020, como uma emergência de saúde pública de interesse internacional (BASTOS LS, et al., 2020). Poucas semanas após, no dia 11 de março do mesmo ano, foi estabelecido que a doença se tratava de uma pandemia, termo esse que denota a disseminação de uma patologia de características infecciosas que ocorre em longa extensão geográfica, quase que em um mesmo espaço de tempo (BRASIL, 2020; SILVA FC, et al., 2020). Eventos como esse já causaram historicamente grandes infortúnios à humanidade, como a Peste Negra e a Gripe Espanhola (TUÑAS ITDC, et al., 2020).

Essa patologia atua ligando-se às células-alvo através da enzima conversora de angiotensina 2 (ECA2), apresentando taxa de letalidade que pode variar de acordo com a idade dos indivíduos, sendo maior em pacientes acima de 60 anos, portadores de comorbidades, como hipertensão arterial e diabetes (FANG L, et al., 2020; TUÑAS ITDC, et al., 2020). Seus sintomas mais incidentes são febre, tosse e fadiga, havendo também outros não tão incidentes, como a produção de escarro, dor de cabeça, hemoptise, diarreia, dispneia e linfopenia (ROTHAN HA e BYRAREDDY SN, 2020).

Sua transmissão se dá principalmente através de contato direto ou indireto com saliva ou fluidos contaminados e pode ocorrer inclusive a partir de paciente assintomáticos, caracterizando, então, uma situação de alarme para profissionais da radiologia odontológica, pelo fato destes estarem comumente em proximidade com a face do paciente e também em contato com mucosas, saliva, possivelmente sangue e também aerossóis provenientes da fala, tosse, espirro ou até da própria respiração do indivíduo (TUÑAS ITDC, et al., 2020).

Devido ao alto grau de transmissibilidade do vírus SARS-CoV-2, tem-se enfatizado o uso dos Equipamentos de Proteção Individual (EPIs) pelos profissionais de saúde e também por toda população em geral. Nesse segundo grupo pode ser citado, principalmente, a popularização do uso de máscaras, álcool em gel $70 \%$ e protetores faciais. 
Compreendidos no grupo citado, estão os profissionais incumbidos aos relevantes serviços realizados em clínicas de radiologia odontológicas, sejam cirurgiões-dentistas ou técnicos especializados. Esses profissionais, por vezes, apresentam um maior risco de contaminação devido ao maior contato com o paciente durante os procedimentos realizados para a obtenção das imagens radiológicas (CDC, 1993; ARAUJO-FILHO JAB, et al., 2020). Além disso, não apenas a contaminação entre paciente e profissional é uma realidade, mas também a contaminação entre pacientes que pode ocorrer devido à rotatividade destes no consultório odontológico (GALVANI LR, et al., 2004).

Nessa perspectiva, a biossegurança, termo em que pode ser definido etimologicamente como segurança à vida, ganha uma importância ainda maior, especialmente por ser, até o momento, o método mais eficaz para impedir o contágio e a propagação da doença no ambiente de trabalho dos profissionais da saúde (FRANÇA SRD, et al., 2017).

Considerando que não existem no meio cientifico dados relativos ao funcionamento de clínicas de radiologia odontológica no Brasil, durante o estado de pandemia da COVID-19, e pela falta de políticas de proteção contra o vírus específicas para o ambiente, objetivou-se, com esse trabalho inédito, avaliar o funcionamento e as medidas de segurança das clínicas de radiologia odontológica na região nordeste do Brasil, durante a pandemia da COVID-19. A divulgação desses importantes dados dará suporte a novas produções sobre a temática, com possibilidade de coadjuvar no desenvolvimento de políticas de prevenção contra os coronavírus.

\section{MÉTODOS}

Utilizou-se uma abordagem indutiva, com procedimento estatístico-descritivo e técnica de observação indireta (MARCONI MA e LAKATOS EM, 2017). O material de análise do presente artigo consistiu em sítios eletrônicos (homepages) e perfis de redes sociais virtuais das clínicas de radiologia odontológica dos nove estados do nordeste do Brasil (Alagoas, Bahia, Ceará, Maranhão, Paraíba, Pernambuco, Piauí, Rio Grande do Norte e Sergipe). Os dados foram coletados no período de março a julho de 2020.

Para a busca destes sítios eletrônicos utilizou-se a ferramenta de busca disponível no Google e no próprio aplicativo que dá acesso a essas redes. As palavras-chave utilizadas para as buscas no Google e Facebook® foram: "Clínica de radiologia odontológica", "Covid-19", "Nordeste", Biossegurança", "Teleodontologia". Já para a busca no Instagram $\AA_{\text {: }}$ "Atendimento odontológico", "Clínica de radiologia odontológica", "Especialidade(s) radiologia odontológica(s)", "Radiologia especializada".

Após a busca inicial, foram aplicados os critérios de elegibilidade do estudo. Um mesmo pesquisador avaliou cada página quanto aos critérios de inclusão, isto é, se era de acesso público, se potencialmente pertencia a uma clínica de radiologia odontológica de um estado do nordeste do Brasil e se as postagens foram publicadas após 21 de março de 2020, data em que o Ministério da Saúde orientou suspensão dos atendimentos odontológicos eletivos em território nacional. Aos perfis que atenderam a esses critérios, aplicaram-se os critérios de exclusão: perfis de consultórios odontológicos, perfis de clínicas de radiologia odontológica de estados fora do Nordeste e de outros países. Dos perfis selecionados no Facebook® avaliaram-se a descrição do usuário e os álbuns de fotos. Já no Instagram ${ }^{\circledR}$ foram analisadas informações da "bio" e postagens do "feed" ou "stories" e suas respectivas legendas. Assim, foram selecionadas 162 clínicas de radiologia odontológica.

A partir dos sítios eletrônicos selecionados $(n=162)$, foram coletadas as seguintes informações: 1- se a clínica fechou em algum momento no mês de março; 2- se a clínica fechou em algum momento no mês de abril; 3- se houve mudanças de horário ao abrir; 4- se o atendimento realizado era comum ou emergencial; 5se houve uso de alguma medida de prevenção, cuidado ou instruções para com os pacientes; 6 - se a clínica disponibilizou os exames radiográficos pela internet; 7- se o horário de funcionamento no mês de julho normalizou. Os dados foram organizados em uma planilha elaborada no Microsoft Office Excel 2007, procedendo-se a análise descritiva. Este estudo não foi submetido à apreciação de Comitê de Ética em Pesquisa (CEP), pois trata-se de estudos que coletam informações de sítios eletrônicos e perfis públicos de redes sociais virtuais. 


\section{RESULTADOS}

Foram avaliadas 162 (100\%) clínicas de radiologia odontológica na região Nordeste do Brasil, dessas, 78 $(48,14 \%)$ informaram o fechamento total em algum momento durante o mês de março (Gráfico 1). Já no mês de abril, o número diminuiu para 65 (40,12\%) (Gráfico 2).

Em março, o estado do Maranhão (MA) foi o que apresentou o maior percentual de clínicas que permaneceram funcionando, contabilizando um total de 7 (33,33\%) das 21 (100\%) clínicas analisadas no estado. No mês seguinte, essa posição foi ocupada por Alagoas (AL), com 7 (53,85\%) clinicas atuantes. Em ambos os meses, o estado do Pernambuco (PE) obteve o maior percentual de clínicas que interromperam temporariamente seus serviços, onde das 17 (100\%) clínicas analisadas, 14 (82,35\%) permaneceram fechadas, apresentando apenas $3(17,65 \%)$ clínicas realizando serviços radiológicos na época analisada (Quadro 1).

Gráfico 1 - Percentual acerca do funcionamento das clínicas de radiologia odontológica, na região Nordeste do Brasil, durante o mês de Março do ano 2020.

\section{Março}

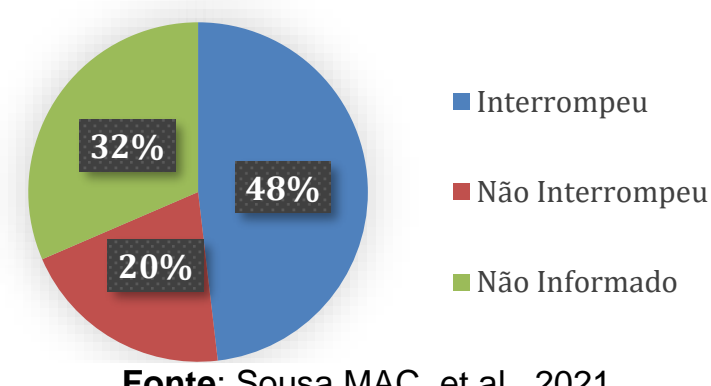

Fonte: Sousa MAC, et al., 2021.

Gráfico 2 - Percentual acerca do funcionamento das clínicas de radiologia odontológica, na região Nordeste do Brasil, durante o mês de Abril do ano 2020.

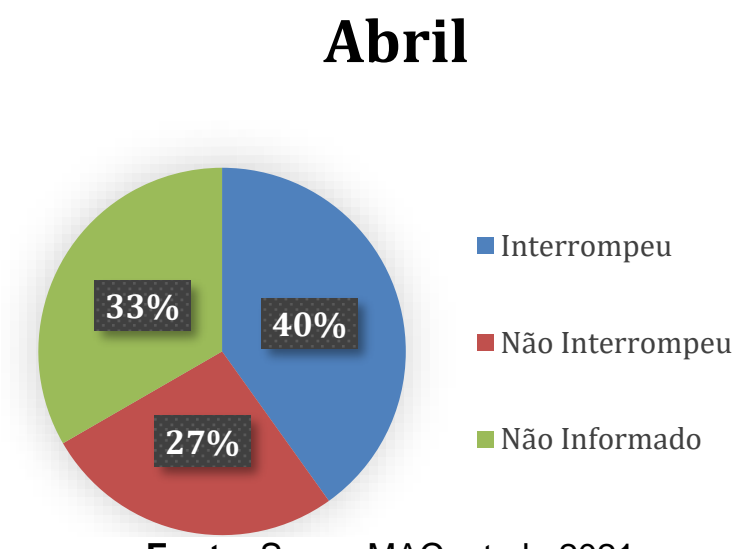

Fonte: Sousa MAC, et al., 2021.

Apenas 51 (31,48\%) clínicas informaram realizar unicamente atendimento emergencial e $44(27,16 \%)$ delas realizaram mudanças nos horários de funcionamento durante os meses de março e de abril. No mês de julho, 60 (37,03\%) das clínicas apresentavam completo funcionamento, com normalidade de horários e sem qualquer tipo de restrição de atendimento.

O número de clínicas que informaram realizar alguma medida de prevenção, cuidado ou instruções relativas ao atual problema foi de $85(52,46 \%)$. Observaram-se $95(58,64 \%)$ clínicas que comunicaram disponibilizar o acesso ao resultado do exame radiográfico por algum tipo de plataforma online e 44 (27,16\%) delas mudaram seu horário de funcionamento em algum momento durante o período analisado. 
Quadro 1 - Dados acerca do funcionamento das clínicas de radiologia odontológica do Nordeste durante os meses de março, abril e julho de 2020.

\begin{tabular}{|c|c|c|c|c|c|c|c|c|c|c|}
\hline \multirow[b]{2}{*}{ Questionário } & \multicolumn{9}{|c|}{ Estados } & \multirow[b]{2}{*}{ Total } \\
\hline & Alagoas & Bahia & Ceará & Maranhão & Paraíba & Pernambuco & Piauí & $\begin{array}{l}\text { Rio Grande } \\
\text { do Norte }\end{array}$ & Sergipe & \\
\hline \multirow{3}{*}{$\begin{array}{l}\text { A clínica fechou em } \\
\text { algum momento no } \\
\text { mês de março? }\end{array}$} & Sim: 8 & Sim: 19 & Sim: 10 & Sim: 2 & Sim: 6 & Sim: 14 & Sim: 4 & Sim: 8 & Sim: 7 & Sim: 78 \\
\hline & Não: 3 & Não: 12 & Não: 1 & Não: 7 & Não: 1 & Não: 1 & Não: 1 & Não: 5 & Não: 2 & Não: 33 \\
\hline & $\begin{array}{c}\text { Não } \\
\text { informado: } 2\end{array}$ & $\begin{array}{l}\text { Não } \\
\text { informado: } 10\end{array}$ & $\begin{array}{c}\text { Não } \\
\text { informado: } 10\end{array}$ & $\begin{array}{c}\text { Não } \\
\text { informado: } 12\end{array}$ & $\begin{array}{c}\text { Não } \\
\text { informado: } 2\end{array}$ & $\begin{array}{c}\text { Não } \\
\text { informado: } 2\end{array}$ & $\begin{array}{l}\text { Não informado: } \\
7\end{array}$ & $\begin{array}{c}\text { Não } \\
\text { informado: } 5\end{array}$ & $\begin{array}{c}\text { Não } \\
\text { informado: } 1\end{array}$ & $\begin{array}{c}\text { Não } \\
\text { informado: } \\
51\end{array}$ \\
\hline \multirow{2}{*}{$\begin{array}{l}\text { A clínica fechou em } \\
\text { algum momento no } \\
\text { mês de abril? }\end{array}$} & Sim: 4 & Sim: 18 & Sim: 9 & Sim: 2 & Sim: 6 & Sim: 14 & Sim: 1 & Sim: 6 & Sim: 5 & Sim: 65 \\
\hline & $\begin{array}{c}\text { Não } \\
\text { informado: } 2\end{array}$ & $\begin{array}{c}\text { Não } \\
\text { informado: } 10\end{array}$ & $\begin{array}{c}\text { Não } \\
\text { informado: } 10\end{array}$ & $\begin{array}{c}\text { Não } \\
\text { informado: } 12\end{array}$ & $\begin{array}{c}\text { Não } \\
\text { informado: } 2\end{array}$ & $\begin{array}{c}\text { Não } \\
\text { informado: } 2\end{array}$ & $\begin{array}{c}\text { Não informado: } \\
10 \\
\end{array}$ & $\begin{array}{c}\text { Não } \\
\text { informado: } 5\end{array}$ & $\begin{array}{c}\text { Não } \\
\text { informado: } 1\end{array}$ & $\begin{array}{c}\text { Não } \\
\text { informado: } \\
54 \\
\end{array}$ \\
\hline \multirow{3}{*}{$\begin{array}{l}\text { Houve mudanças de } \\
\text { horário ao abrir? }\end{array}$} & Sim: 1 & Sim: 18 & Sim: 1 & Sim: 4 & Sim: 6 & Sim: 4 & Sim: 0 & Sim: 5 & Sim: 5 & Sim: 44 \\
\hline & Não: 10 & Não: 13 & Não: 2 & Não: 5 & Não: 0 & Não: 2 & Não: 6 & Não: 8 & Não: 4 & Não: 50 \\
\hline & $\begin{array}{c}\text { Não } \\
\text { informado: } 2\end{array}$ & $\begin{array}{l}\text { Não } \\
\text { informado: } 10\end{array}$ & $\begin{array}{c}\text { Não } \\
\text { informado: } 18\end{array}$ & $\begin{array}{c}\text { Não } \\
\text { informado: } 12\end{array}$ & $\begin{array}{c}\text { Não } \\
\text { informado: } 3\end{array}$ & $\begin{array}{c}\text { Não } \\
\text { informado: } 11\end{array}$ & $\begin{array}{l}\text { Não informado: } \\
6 \\
\end{array}$ & $\begin{array}{c}\text { Não } \\
\text { informado: } 5\end{array}$ & $\begin{array}{c}\text { Não } \\
\text { informado: } 1\end{array}$ & $\begin{array}{c}\text { Não } \\
\text { informado: } \\
68 \\
\end{array}$ \\
\hline \multirow{3}{*}{$\begin{array}{l}\text { O atendimento } \\
\text { realizado era } \\
\text { comum ou } \\
\text { emergencial? }\end{array}$} & Comum: 3 & Comum: 8 & Comum: 0 & Comum: 7 & Comum: 2 & Comum: 0 & Comum: 5 & Comum: 10 & Comum: 3 & Comum: 38 \\
\hline & $\begin{array}{c}\text { Emergencial: } \\
8\end{array}$ & $\begin{array}{l}\text { Emergencial: } \\
23 \\
\end{array}$ & $\begin{array}{l}\text { Emergencial: } \\
3 \\
\end{array}$ & Emergencial: 2 & $\begin{array}{l}\text { Emergencial: } \\
4\end{array}$ & $\begin{array}{l}\text { Emergencial: } \\
2\end{array}$ & Emergencial: 1 & $\begin{array}{c}\text { Emergencial: } \\
3\end{array}$ & $\begin{array}{c}\text { Emergencial: } \\
5\end{array}$ & $\begin{array}{c}\text { Emergencial: } \\
51\end{array}$ \\
\hline & $\begin{array}{c}\text { Não } \\
\text { informado: } 2\end{array}$ & $\begin{array}{c}\text { Não } \\
\text { informado: } 10\end{array}$ & $\begin{array}{c}\text { Não } \\
\text { informado: } 18\end{array}$ & $\begin{array}{c}\text { Não } \\
\text { informado: } 12\end{array}$ & $\begin{array}{c}\text { Não } \\
\text { informado: } 3\end{array}$ & $\begin{array}{c}\text { Não } \\
\text { informado: } 15\end{array}$ & $\begin{array}{l}\text { Não informado: } \\
6\end{array}$ & $\begin{array}{c}\text { Não } \\
\text { informado: } 5\end{array}$ & $\begin{array}{c}\text { Não } \\
\text { informado: } 2\end{array}$ & $\begin{array}{c}\text { Não } \\
\text { informado: } \\
73\end{array}$ \\
\hline \multirow{3}{*}{$\begin{array}{c}\text { Houve uso de } \\
\text { alguma medida de } \\
\text { prevenção, cuidado } \\
\text { ou instruções para } \\
\text { com os pacientes? }\end{array}$} & Sim: 8 & Sim: 31 & Sim: 2 & Sim: 9 & Sim: 5 & Sim: 12 & Sim: 4 & Sim: 12 & Sim: 2 & Sim: 85 \\
\hline & Não: 3 & Não: 0 & Não: 13 & Não: 0 & Não: 3 & Não: 5 & Não: 2 & Não: 0 & Não: 7 & Não: 33 \\
\hline & $\begin{array}{c}\text { Não } \\
\text { informado: } 2\end{array}$ & $\begin{array}{l}\text { Não } \\
\text { informado: } 10\end{array}$ & $\begin{array}{c}\text { Não } \\
\text { informado: } 6\end{array}$ & $\begin{array}{c}\text { Não } \\
\text { informado: } 12\end{array}$ & $\begin{array}{c}\text { Não } \\
\text { informado: } 1\end{array}$ & $\begin{array}{c}\text { Não } \\
\text { informado: } 0\end{array}$ & $\begin{array}{l}\text { Não informado: } \\
6\end{array}$ & $\begin{array}{c}\text { Não } \\
\text { informado: } 6\end{array}$ & $\begin{array}{c}\text { Não } \\
\text { informado: } 1\end{array}$ & $\begin{array}{l}\text { Não } \\
\text { informado: } \\
\quad 44\end{array}$ \\
\hline \multirow{3}{*}{$\begin{array}{l}\text { A clínica } \\
\text { disponibilizou os } \\
\text { exames } \\
\text { radiográficos pela } \\
\text { internet? }\end{array}$} & Sim: 6 & Sim: 26 & Sim: 14 & Sim: 12 & Sim: 8 & Sim: 15 & Sim: 4 & Sim: 8 & Sim: 2 & Sim: 95 \\
\hline & Não: 5 & Não: 14 & Não: 0 & Não: 5 & Não: 0 & Não: 2 & Não: 2 & Não: 5 & Não: 5 & Não: 38 \\
\hline & $\begin{array}{c}\text { Não } \\
\text { informado: } 2\end{array}$ & $\begin{array}{c}\text { Não } \\
\text { informado: } 1\end{array}$ & $\begin{array}{c}\text { Não } \\
\text { informado: } 7\end{array}$ & $\begin{array}{c}\text { Não } \\
\text { informado: } 4\end{array}$ & $\begin{array}{c}\text { Não } \\
\text { informado: } 1\end{array}$ & $\begin{array}{c}\text { Não } \\
\text { informado: } 0\end{array}$ & $\begin{array}{l}\text { Não informado: } \\
6\end{array}$ & $\begin{array}{c}\text { Não } \\
\text { informado: } 5\end{array}$ & $\begin{array}{c}\text { Não } \\
\text { informado: } 3\end{array}$ & $\begin{array}{c}\text { Não } \\
\text { informado: } \\
29\end{array}$ \\
\hline \multirow{3}{*}{$\begin{array}{l}\text { O horário de } \\
\text { funcionamento no } \\
\text { mês de julho } \\
\text { normalizou? }\end{array}$} & Sim: 0 & Sim: 17 & Sim: 4 & Sim: 14 & Sim: 5 & Sim: 3 & Sim: 0 & Sim: 10 & Sim: 7 & Sim: 60 \\
\hline & Não: 9 & Não: 11 & Não: 1 & Não: 2 & Não: 0 & Não: 3 & Não: 5 & Não: 4 & Não: 0 & Não: 35 \\
\hline & $\begin{array}{c}\text { Não } \\
\text { informado: } 4\end{array}$ & $\begin{array}{c}\text { Não } \\
\text { informado: } 13\end{array}$ & $\begin{array}{c}\text { Não } \\
\text { informado: } 16\end{array}$ & $\begin{array}{c}\text { Não } \\
\text { informado: } 5\end{array}$ & $\begin{array}{c}\text { Não } \\
\text { informado: } 4\end{array}$ & $\begin{array}{c}\text { Não } \\
\text { informado: } 11\end{array}$ & $\begin{array}{l}\text { Não informado: } \\
7\end{array}$ & $\begin{array}{c}\text { Não } \\
\text { informado: } 4\end{array}$ & $\begin{array}{c}\text { Não } \\
\text { informado: } 3\end{array}$ & $\begin{array}{c}\text { Não } \\
\text { informado: } \\
67\end{array}$ \\
\hline
\end{tabular}

Fonte: Sousa MAC, et al., 2021. 
O tipo mais comum de exame radiográfico oferecido foi a radiografia panorâmica, disponibilizada em 144 $(88,88 \%)$ das $162(100 \%)$ clínicas. Em seguida, a radiografia periapical oferecida por $143(88,27 \%)$ das clínicas e em terceiro lugar a radiografia interproximal, sendo ofertada por $126(77,78 \%)$ dos serviços de radiologia odontológica. A telerradiografia frontal foi a menos ofertada, com um número de $99(61,11 \%)$ clínicas disponíveis para realizar esse exame (Quadro 2).

Quadro 2 - Exames realizados nas clínicas de radiologia odontológica do Nordeste.

\begin{tabular}{|c|c|c|c|c|c|c|c|c|c|c|}
\hline $\begin{array}{c}\text { Tipos de exames } \\
\text { realizados }\end{array}$ & Alagoas & Bahia & Ceará & Maranhão & Paraíba & Pernambuco & Piauí & $\begin{array}{c}\text { Rio } \\
\text { Grande do } \\
\text { Norte }\end{array}$ & Sergipe & Total \\
\hline Periapical & 9 & 41 & 16 & 21 & 9 & 14 & 7 & 18 & 8 & 143 \\
\hline Interproximal & 4 & 41 & 16 & 18 & 8 & 12 & 3 & 17 & 7 & 126 \\
\hline Oclusal & 6 & 26 & 16 & 14 & 8 & 11 & 2 & 14 & 7 & 104 \\
\hline Panorâmica & 11 & 41 & 16 & 21 & 9 & 14 & 7 & 17 & 8 & 144 \\
\hline $\begin{array}{c}\text { Telerradiografia } \\
\text { frontal }\end{array}$ & 8 & 25 & 15 & 17 & 4 & 6 & 6 & 11 & 7 & 99 \\
\hline $\begin{array}{c}\text { Telerradiografia } \\
\text { lateral }\end{array}$ & 6 & 25 & 15 & 17 & 4 & 9 & 6 & 11 & 7 & 100 \\
\hline $\begin{array}{c}\text { Tomografia } \\
\text { computadorizada }\end{array}$ & 9 & 29 & 16 & 14 & 7 & 13 & 5 & 9 & 8 & 110 \\
\hline
\end{tabular}

Fonte: Sousa MAC, et al., 2021.

\section{DISCUSSÃO}

A pandemia da COVID-19 representa o maior desafio sanitário global do século XXI, sendo a primeira vez em que um vírus alcança proporções alarmantes, de modo a acometer todos os continentes e acarretar impactos inestimáveis, afetando direta e/ou indiretamente a saúde e a economia da população mundial (BRITO SBP, et al., 2020). O coronavírus apresenta-se como uma doença de grande transmissibilidade e gravidade clínica, conforme relatado pela letalidade em diferentes países, sendo, portanto, considerada uma emergência de saúde pública de interesse internacional (BRASIL, 2020). Diante a esse cenário, torna-se urgente a necessidade de capacitar e qualificar profissionais da área da saúde no enfrentamento dessa doença (BRITO SBP, et al., 2020).

A COVID-19 apresenta especial impacto na Odontologia, uma vez que estudos indicam que os sítios da cavidade oral são possíveis focos de entrada do coronavírus nas células do hospedeiro humano (CARRER FCA, et al., 2020). Sendo assim, Pinto LG, et al., (2020) afirmam que é de responsabilidade dos cirurgiõesdentistas buscar minimizar ao máximo a disseminação de patógenos no decorrer de qualquer assistência odontológica prestada, apresentando um papel de extrema importância na prevenção da transmissão do vírus.

A assistência odontológica apresenta um alto risco para a disseminação da COVID-19, devido à alta carga viral presente nas vias aéreas superiores dos pacientes infectados e à grande possibilidade de exposição aos materiais biológicos, proporcionado pela geração de aerossóis durante os procedimentos (ANVISA, 2020). A proximidade entre o cirurgião-dentista e o paciente, exposição à saliva e outros fluidos, utilização de instrumentos manuais, cortantes ou não, que podem estar contaminados, são características da prática odontológica (FRANCO AG, et al., 2020). Logo, faz-se necessário um cuidado redobrado em relação ao manejo do paciente, limpeza do consultório e proteção do profissional e auxiliares diante da COVID-19 (FRANCO AG, et al., 2020). Sendo assim, Spagnuolo, et al., (2020) descreveram os cirurgiões-dentistas como os profissionais mais expostos ao vírus e com maiores chances de serem afetados pela doença.

As clínicas de radiologia odontológica, no entanto, são consideradas ambientes de grande potencial de infecção cruzada, tendo em vista os locais de maior contato entre o operador e os equipamentos. Embora a realização das tomadas radiográficas na Odontologia sejam geralmente consideradas procedimentos semicríticos e não invasivos, muitas doenças infecciosas podem ser transmitidas por meio da saliva (JARDIM JÚNIOR EG, et al., 2011). 
Para Jardim Júnior EG, et al., (2011), os locais com maior potencial de contaminação, durante as tomadas radiográficas odontológicas, correspondem às luvas do operador e aos locais por elas tocados, como o cabeçote do aparelho de raios- $X$ e as soluções para o processamento radiográfico, uma vez que, pelo fato destas últimas serem utilizadas por um período longo e contínuo, tornam-se passíveis de atuarem como veículos de infecções, particularmente para microrganismos e vírus presentes na saliva. Em consonância a isto, Silva, et al., (2003) relatam em seus estudos que as técnicas radiográficas intrabucais promovem uma maior possibilidade de contaminação por microrganismos potencialmente contagiosos.

Apesar da existência de um potencial risco de contaminação, as imagens radiológicas representam um papel crucial na Odontologia moderna, sendo um exame complementar imprescindível usado por boa parte das especialidades odontológicas (PEREIRA GAM, et al., 2017). Devido a isso, houve praticamente a impossibilidade da completa inércia dos serviços de radiologia odontológica, durante todo esse tempo, o que clarifica uma tendência ao funcionamento dessas clinicas, mesmo que seja somente no atendimento de casos de urgência e emergência, ao transpor dos meses analisados.

Sob essa perspectiva, medidas foram adotadas para minimizar o contágio da COVID-19 nos atendimentos odontológicos, como evitar as radiografias intrabucais, de modo a reduzir o estímulo da salivação e tosse, e dar preferência aos exames extrabucais (radiografias panorâmicas ou tomografias computadorizadas de feixe cônico) (ANVISA, 2020). Outra medida preconizada como forma de prevenção e proteção é priorizar o atendimento de urgência e emergência, restringindo e adiando os serviços eletivos, estratégia esta que pode ser adotada em situações de pandemia para diminuir a circulação de pessoas e reduzir a execução de procedimentos que possam gerar aerossóis e, consequentemente, a transmissão do vírus (CFO, 2020).

Entendendo-se, entretanto, que ainda há uma grande diversidade de situações em que as radiografias intrabucais apresentam-se como indispensáveis, como pode ser exemplificado em casos de tratamentos endodônticos, onde as tomadas radiográficas periapicais, presentes em $88,27 \%$ dos locais que oferecem serviços de radiologia odontológica no Nordeste, são rotineiramente consideradas indispensáveis para tais fins. Desprezando-se as radiografias extrabucais, como a radiografia panorâmica $(88,88 \%)$, que apesar de ser mais frequentemente presente quando comparadas às periapicais nas clinicas de radiologia, não apresentam tal riqueza de detalhes do órgão dental necessária, sendo essa crucial para fins de diagnóstico e orientação ao longo da terapia endodôntica, como em casos onde há necessidade de análise da condição óssea periapical e também de lesões em tal região (SEWELL CMD, et al., 1999).

Ademais, seguindo as recomendações dos órgãos de saúde, algumas clínicas de radiologia, na região do Nordeste, fecharam nos meses de março $(48,14 \%)$ e abril $(40,12 \%)$, com o intuito de dirimir a propagação do vírus. Essa medida possivelmente provocou um impacto na vida dos pacientes, visto que estes não puderam realizar seus devidos exames, preventivos ou ortodônticos. Além disso, pode ter impossibilitado os pacientes de obter um diagnóstico precoce radiográfico, contribuindo, de certa forma, para uma severidade de problemas e doenças orais, como extensões de cáries, lesões bucais, dentre outras.

Mudanças de horários nos atendimentos foram alteradas por $27,16 \%$ das clínicas do Nordeste. Estas optaram por um atendimento com agendamento prévio (através de chamadas telefônicas, aplicativos de mensagens ou videoconferências), marcação de horário, redução da quantidade de pacientes por turno e aumento de intervalo entre as consultas para realização de uma higiene local mais eficaz, de modo a evitar aglomerações na recepção e corredores dos consultórios odontológicos.

Seguindo as condutas orientadas pelo Conselho Federal de Odontologia (CFO), as clínicas priorizaram a realização da triagem prévia de pacientes e funcionários, com o intuito de buscar informações que indiquem uma possível contaminação pelo vírus (febre, tosse, dor de garganta e dores musculares) e orientaram a ausência de acompanhantes para a consulta, exceto nos casos em que houver a necessidade de assistência, como, por exemplo, pacientes pediátricos, pessoas com necessidades especiais e pacientes idosos (ANVISA, 2020).

De modo a orientar as medidas de precaução para os pacientes, foram utilizadas, por muitas clínicas, alertas visuais, através de imagens ilustrativas, cartazes, sinalizações, placas e pôsteres, como a manutenção 
de distanciamento social apropriado (sinalizando pelo menos 1 metro de distância entre as pessoas), lavagem das mãos, uso de máscaras e álcool em gel 70\%. Visando a redução da transmissão do novo coronavírus, $52,46 \%$ das clínicas de radiologia informaram fornecer aos pacientes e acompanhantes algum tipo de instrução como medida de prevenção, uma vez que estes locais promovem grande risco de infecção viral.

Dado as atualizações dos paradigmas de biossegurança nas clínicas de radiologia, faz-se necessário que o profissional da saúde utilize máscaras N95/PFF2 ou equivalentes, toucas descartáveis, óculos de proteção, máscara facial, jaleco de tecido, avental cirúrgico descartável sobreposto, luvas de látex ou nitrílicas descartáveis e protetores para os sapatos (FARIA CAB, et al., 2020). Ademais, os itens utilizados na cavidade oral do paciente devem receber bastante atenção na esterilização, recomendando-se a utilização de autoclaves, visando e assegurando a eliminação dos microrganismos (FARIA CAB, et al., 2020).

Além disso, foi intensificado a realização da limpeza e desinfecção de superfícies do consultório (maçanetas, cadeiras e banheiro), com Hipoclorito de Sódio a $0,1 \%$ ou Peróxido de Hidrogênio a $0,5 \%$ e álcool a $70 \%$ (CFO, 2020). As salas de espera, que concentram um fluxo elevado de pessoas, necessitaram ser adaptadas, a fim de evitar aglomerações e minimizar o tempo de espera. Recomendou-se que o ambiente clínico detenha boa ventilação, distribuição de máscaras descartáveis e medidas adicionais que objetivem a diminuição no uso de itens compartilhados. Objetos que não possam ser facilmente desinfetados, como revistas ou outros materiais de leitura e brinquedos, precisaram ser retirados. Ademais, foi enfatizado a disponibilização de materiais de higiene, como sabão, para limpeza das mãos e rosto (PINTO LG, et al., 2020).

No cenário pandêmico atual, outra alternativa foi aprimorada para favorecer o exercício da radiologia na prática clínica: a Teleodontologia. Carrer, et al., (2020) afirmaram que esta ferramenta tem se mostrado eficaz tanto no custo quanto na disseminação do acesso, com vantagens relacionadas ao aumento da resolutividade, com ganhos significativos de qualidade e precisão da imagem, à redução do tempo de espera e dos custos de tratamento.

Esse serviço de Telessaúde tem-se apresentado como um meio benéfico na rotina clínica radiológica durante a crise da COVID-19, sendo utilizada por 58,64\% das clínicas do Nordeste. Com o intuito de informar, reduzir e ajudar no controle do risco de contaminação do vírus, a Teleodontologia dispõe os exames de maneira prática, por meio de ferramentas digitais, como sites e aplicativos de celular. Vale salientar, também, que este meio contribui com a sustentabilidade, de modo a reduzir o uso de papel, plásticos e reagentes químicos para a confecção dos laudos de exames radiológicos.

Novos meios de proteção foram adaptados para um cenário de pós-pandemia da COVID-19, assim como a intensificação das barreiras de biossegurança nas clínicas radiológicas (ZHU HD, et al., 2020). Dessa forma, durante os procedimentos, toda a equipe envolvida deverá seguir um protocolo de proteção de infecção de alto padrão, incluindo o uso completo dos EPIs, com o intuito de evitar a transferência de patógenos presentes em filmes e sensores radiográficos para o ambiente de trabalho (SALZEDAS LMP, et al., 2020).

\section{CONSIDERAÇÕES FINAIS}

Os profissionais da Odontologia apresentam relevante atuação frente à pandemia da COVID-19, sendo estes importantes meios de informação e conscientização da doença. Diante ao cenário pandêmico atual, mudanças nas práticas de controle de infeção fizeram-se necessárias, devido ao alto risco de propagação do vírus nas clínicas odontológicas, de modo a minimizar a disseminação de patógenos potencialmente contagiosos, tornando, como consequência, imprescindível a utilização de técnicas assépticas. Sendo assim, os resultados desse estudo revelaram a necessidade da evolução dos parâmetros de biossegurança e da importância dos procedimentos de desinfecção e limpeza das superfícies e instrumentais na rotina da radiologia odontológica, na região do Nordeste, durante esse período. Além disso, foi destacada a importância da implementação das normas de segurança, adotadas pelos órgãos de saúde, por meio de medidas de autoproteção e prevenção da propagação do vírus. 


\section{REFERÊNCIAS}

1. ANDERSEN KG, et al. The proximal origin of SARS-CoV-2. Nature medicine, $2020 ; 26(4): 450-452$.

2. ANVISA. AGÊNCIA NACIONAL DE VIGILÂNCIA SANITÁRIA. Orientações para serviços de saúde: medidas de prevenção e controle que devem ser adotadas durante a assistência aos casos suspeitos ou confirmados de infecção pelo coronavírus (sars-cov-2). Disponível em: http://portal.anvisa.gov.br/documents/33852/271858/Nota+T\%C3\% A9cnica+n+04-2020+GVIMS-GGTES-ANVISA/ab598660-3de4-4f14-8e6f-b9341c196b28. Acesso em: 31 de ago. de 2020.

3. ARAUJO-FILHO JAB, et al. Pneumonia por COVID-19: qual o papel da imagem no diagnóstico? Jornal Brasileiro de Pneumologia, 2020; 46(2).

4. BASTOS LS, et al. COVID-19 e hospitalizações por SRAG no Brasil: uma comparação até a $12^{\mathrm{a}}$ semana epidemiológica de 2020. Reports In Public Health, 2020; 36(4).

5. BRASIL. Ministério da Saúde. Protocolo de manejo clínico do coronavírus (COVID-19) na atenção primária à saúde. Disponível em: https://saude.rs.gov.br/upload/arquivos/202004/14140606-4-ms-protocolomanejo-aps-ver07abril.pdf. Acesso em: 31 de ago. de 2020.

6. BRITO SBP, et al. Pandemia da COVID-19: o maior desafio do século XXI. Revista Visa Em Debate, 2020; 8(2).

7. CARRER FCA, et al. Teleodontologia e SUS: uma importante ferramenta para a retomada da Atenção Primária à Saúde no contexto da pandemia de COVID-19. Pesquisa Brasileira em Odontopediatria e Clínica Integrada, 2020.

8. CDC. CENTERS FOR DISEASE CONTROL AND PREVENTION. Recommended Infection Control Practices for Dentistry. Morbidity and Mortality Weekly Report. May 28, 1993, 42. Disponível em: http://www.cdc.gov/mmwr/pdf/rr/rr4208.pdf. Acesso em 09 set 2020.

9. CFO. CONSELHO FEDERAL DE ODONTOLOGIA. 2020. Nota técnica GVIMS/GGTES/ANVISA no 04/2020. Disponível em: https://website.cfo.org.br/wp-content/uploads/2020/04/Nota-Tecnica-Anvisa-CFO-contra-covid-19.pdf. Acesso em: 02 set. 2020.

10. CFO. CONSELHO FEDERAL DE ODONTOLOGIA. 2020. Recomendações para atendimentos odontológicos em tempos de covid-19, 2020. Disponível em: http://website.cfo.org.br/wp-content/uploads/2020/05/Cartilha-cfocovid19.pdf. Acesso em: 02 set. 2020.

11. DA SILVA HHC, et al. Narrativas sobre a pandemia por covid-19 nos estados do Amazonas e Roraima. Somanlu: Revista de Estudos Amazônicos, 2020; 1(1): 33-49.

12. FANG L, et al. Are patients with hypertension and diabetes mellitus at increased risk for COVID-19 infection? The Lancet. Respiratory Medicine, 2020; 8(4): 21.

13. FARIA CAB, et al. A importância da prática odontológica segura diante da Covid-19: uma revisão da literatura. Braz. J. of Develop., 2020; 6(8): 56206-56213.

14. FRANÇA SRD, et al. Percepção de clientes em relação às normas de biossegurança utilizadas nos centros de embelezamento e estética. Revista Ceuma Perspectivas, 2017; 30(3): 101-114.

15. FRANCO AG, et al. Importância da conduta do cirurgião-dentista frente à contenção e prevenção do Covid-19. InterAm J Med Health, 2020.

16. GALVANI LR, et al. Utilização dos métodos de biossegurança nos consultórios odontológicos da cidade de Porto Alegre-RS. Stomatos, 2004; 10(18): 7-13.

17. JARDIM JÚNIOR EG, et al. Contaminação microbiana das soluções de processamento radiográfico: risco de infecção cruzada. Pesquisa Brasileira em Odontopediatria e Clínica Integrada, 2011; 11(2): 193-198.

18. LANA RM, et al. Emergência do novo coronavírus (SARS-CoV-2) e o papel de uma vigilância nacional em saúde oportuna e efetiva. Cadernos de Saúde Pública, 2020; 36.

19. MARCONI MA, LAKATOS EM. Fundamentos de metodologia científica. 8a ed. São Paulo: Atlas, 2017.

20. PENG X, et al. Transmission routes of 2019-nCoV and controls in dental practice. International journal of oral science, 2020; 12(9).

21. PEREIRA GAM, et al. O ensino da Radiologia: uma análise dos currículos da área da saúde de instituições de ensino superior na região sul do Brasil. Revista Brasileira de Educação Médica, 2017; 41(2): 251-259.

22. PINTO LG, et al. Recommendations for dental practices during Covid-19 pandemic. Research, Society and Development, 2020; 9(7).

23. ROTHAN HA, BYRAREDDY SN. The epidemiology and pathogenesis of coronavirus disease (COVID-19) outbreak. Journal of autoimmunity, 2020; 109.

24. SALZEDAS LMP, et al. Clínica radiológica em tempos de pandemia: impactos e condutas na prática odontológica. Arch Health Invest, 2020; 9(4): 308-313.

25. SEWELL CMD, et al. Avaliação do tratamento endodôntico em radiografias periapicais e panorâmicas. Revista de Odontologia da Universidade de São Paulo, 1999; 3: 295-302.

26. SILVA FC, et al. Estudo da contaminação microbiológica em equipamentos radiográficos. Revista Biociências, Taubaté, 2003; 9(2): 35-43.

27. SPAGNUOLO G, et al. COVID-19 outbreak: na overview on dentistry. International Journal of Environmental Research and Public Health, 2020; 17.

28. TUÑAS ITDC, et al. Doença pelo Coronavírus 2019 (COVID-19): Uma abordagem preventiva para Odontologia. Revista Brasileira de Odontologia, 2020; 77: 1-7.

29. WHO. World Health Organization. Coronavirus disease (COVID-19) Situation Report - 165. Disponível em: https://apps.who.int/iris/handle/10665/333143. Acesso em 09 set. 2020.

30. ZHU HD, et al. COVID-19: What should interventional radiologists know and what can they do? J Vasc Interv Radiol, $2020 ; 31(6)$. 